\title{
Recent Trends in Biomimetic NADH Regeneration
}

\author{
Tommaso Quinto • Valentin Köhler • \\ Thomas R. Ward
}

Published online: 14 November 2013

(c) Springer Science+Business Media New York 2013

\begin{abstract}
Nicotinamide adenine dinucleotide (NADH) and nicotinamide adenine dinucleotide phosphate constitute a major cost factor in preparative biotransformations. The development of efficient methods for their regeneration with cheap reducing equivalents has been an area of intense research in the last decades. Methods explored include chemical, electrochemical, and photochemical approaches. None of the methods to regenerate NADH has reached an efficiency comparable with enzymatic regeneration (e.g. formate dehydrogenase) which remains the method of choice for most applications. In this review, we summarize primarily organometallic-based approaches for NADH regeneration methods which include non-enzymatic steps, before moving on to the most recent developments in synthetic NADH related transformations. We highlight the frequent problem of mutual inactivation between the organometallic catalyst for $\mathrm{NADH}$ regeneration and the corresponding NADH dependent downstream enzyme. Potential remedies are discussed, such as the compartmentalization of the organometallic complex.
\end{abstract}

Keywords NADH regeneration - Biomimetic chemistry · Pianostool complex ·

Compartmentalization - Mutual inhibition · Transfer hydrogenation

T. Quinto · V. Köhler · T. R. Ward ( $₫)$

Department of Chemistry, University of Basel, Spitalstrasse 51, 4056 Basel, Switzerland

e-mail: thomas.ward@unibas.ch

\author{
Abbreviations \\ NADH Nicotinamide adenine dinucleotide (reduced \\ form) \\ $\mathrm{NAD}^{+} \quad$ Nicotinamide adenine dinucleotide \\ NAD(P)H Nicotinamide adenine dinucleotide phosphate \\ (reduced form) \\ $\mathrm{NAD}(\mathrm{P})^{+} \quad$ Nicotinamide adenine dinucleotide phosphate \\ TEA Triethylamine \\ TEOA Triethanolamine \\ TON Turn over number (mol of product/mol of \\ catalyst) \\ TOF Turn over frequency (mol of product/(mol of \\ catalyst $\times$ time)) \\ Cp* 1,2,3,4,5-Pentamethylcyclopentadienyl \\ Bpy $\quad$ 2,2'-Bipyridine
}

\section{Introduction}

Ever since the groundbreaking work by Abril and Whitesides [1] and Steckhan and colleagues [2] on metal mediated nicotinamide adenine dinucleotide $\left(\mathrm{NAD}^{+}\right)$ regeneration, the field has blossomed and has been reviewed extensively [3-12]. While numerous metal-catalysts have been reported for the efficient reduction of the pyridinium moiety, several studies to date were performed on $\mathrm{NAD}^{+}$(or analogs thereof) in the absence of the nicotinamide adenine dinucleotide (NADH) dependent enzyme. Indeed, combining both enzyme and organometallic catalyst often lead to deactivation of one or both catalytic systems. In this context and following a selection of historically relevant abiotic NADH regeneration systems, we 
present the most promising means to overcome the mutual inhibition challenge.

\section{Pioneering Non-enzymatic Approaches for the Regeneration of Nicotinamide Adenine Dinucleotide Phosphate [NAD(P)H]}

The first electro-enzymatic regeneration of $\mathrm{NAD}(\mathrm{P}) \mathrm{H}$ was reported by the group of Whitesides. For this purpose, they relied on a tungsten cathode to reduce either a disulfide to the corresponding dithiol [13] or methyl viologen [14] to provide the reducing equivalents for the enzymatic reduction of $\mathrm{NAD}^{+}$or nicotinamide adenine dinucleotide phosphate $\left(\mathrm{NADP}^{+}\right)$with either lipoamide dehydrogenase or ferredoxin NADP reductase, respectively. This indirect approach allowed to overcome problems encountered in the direct electrochemical reduction, such as insufficient regioselectivity and radical dimerization [15]. The NADH produced served for the concurrent reduction of pyruvate with lactate dehydrogenase. The methyl viologen mediated NADPH regeneration was coupled to the glutamic dehydrogenase catalysed formation of glutamate from $\alpha$ ketoglutarate.

The first example of indirect chemical regeneration of NADH, was also reported by Whitesides' group in 1981 . They employed a water soluble organometallic diphosphine rhodium(I) catalyst, to convert pyruvate to lactic acid using $\mathrm{H}_{2}(2.72 \mathrm{~atm})$ as reducing agent. In the presence of lactate dehydrogenase, $\mathrm{NAD}^{+}$was reduced to NADH, thus enabling the stereoselective reduction of $(1 R, 4 S)$-Norcamphor with horse liver alcohol dehydrogenase (Fig. 1) [1]. They note that the efficiency of the system is limited by the modest activity [turn over frequency (TOF)] of the rhodium complex in the pyruvate reduction [TOF $\approx 10 \mathrm{~h}^{-1}$, turn over number $(\mathrm{TON})=1,500]$, which nevertheless enables high productivity (TON). The deactivation of the rhodium complex by free thiol groups present on the enzymes was hypothesized. The addition of a fresh batch of the complex was required to complete the reaction.

One of the first attempts to regenerate NADH by a photochemical reduction was reported by Kiwi in 1981 . Here, $\left[\mathrm{Ru}(\mathrm{bpy})_{3}\right]^{2+}$ was activated by irradiation with visible light, in the presence of triethylamine which served as the electron donor (Fig. 2) [16]. In contrast to their proposed final disproportionation step of the NAD radicals to $\mathrm{NAD}^{+}$and NADH [17], Steckhan subsequently showed that the radical dimerises practically exclusively to yield the non-active (NAD) 2 [18].

Steckhan was the first to report an indirect electrochemical NADH regeneration method. In this system, a $\left[\mathrm{Rh}(\mathrm{bpy})_{3}\right]^{3+}$ catalyst is reduced electrochemically to $\left[\mathrm{Rh}(\mathrm{bpy})_{2}\right]^{+}$which subsequently reduces $\mathrm{NAD}^{+}$in buffered aqueous medium which serves as a proton source (Fig. 3). The system was coupled to horse liver alcohol dehydrogenase (HLAD) catalyzed ketone reduction [19]. The use of a $\left[\mathrm{Rh}(\mathrm{bpy})_{3}\right]^{3+}$ mediator prevents the formation of NAD radicals. Indeed, the direct electrochemical reduction of $\mathrm{NAD}^{+}$, requires a potential of $>-1.1 \mathrm{~V}$ versus the $\mathrm{Ag} / \mathrm{AgCl}$ electrode, potentially leading to side-products, including the NAD dimer. In the presence of the redox-mediator, the potential can be reduced to $-850 \mathrm{mV}$ versus $\mathrm{Ag} / \mathrm{AgCl}$ electrode. The authors identified a passivation of the cathode due to the deposition of $\left[\mathrm{Rh}(\mathrm{bpy})_{2}\left(\mathrm{H}_{2} \mathrm{O}\right)_{2}\right] \mathrm{Cl}$ or $\left[\mathrm{Rh}(\mathrm{bpy})_{2}(\mathrm{OH})_{2}\right] \mathrm{Cl}$ leading to low TONs with respect to $\mathrm{Rh}$ $(\mathrm{TON}=2.2)$. Lacking enzyme activity as a possible cause for the low productivity was excluded.

Subsequently, Steckhan reported a photochemical system similar to Kiwi's whereby $\left[\mathrm{Ru}(\mathrm{bpy})_{3}\right]^{2+}$ (used as sensitizer) is activated by visible light [18]. In the presence of triethanolamine (TEOA), $\left[\mathrm{Rh}(\mathrm{bpy})_{3}\right]^{3+}$ is converted to $\left[\mathrm{Rh}(\mathrm{bpy})_{2}\right]^{+}$and reduces $\mathrm{NAD}^{+}$. In subsequent work, they reported an improved version of the electrochemical regeneration. The improvement was mainly achieved by tuning the ligand: substituting the bipyridine by bipyridyl5-sulfonic acid, allowed to reduce the reduction potential to $-730 \mathrm{mV}$ versus $\mathrm{Ag} / \mathrm{AgCl}$ thereby overcoming the formation of NAD radicals. A TOF of $0.5 \mathrm{~h}^{-1}$ and a TON of 19 with respect to $\mathrm{Rh}$ were achieved in the coupled reduction of cyclohexanone to cyclohexanol by HLADH [20].

Importantly, Steckhan introduced $[\mathrm{Cp} * \mathrm{Rh}(\mathrm{bpy}) \mathrm{Cl}]^{+}$to the arena of NADH regeneration. Compared to previous systems, the coupling of this catalyst with LDH shows 20 times higher reduction rates $\left(\mathrm{TOF}=5 \mathrm{~h}^{-1}\right.$, TON $=14$ in respect to $\mathrm{Rh}$ ) in the conversion of pyruvate [2].

In the latter system, the hydride $[\mathrm{Cp} * \mathrm{Rh}(\mathrm{bpy}) \mathrm{H}]^{+}$is the species responsible for $\mathrm{NAD}^{+}$and $\mathrm{NAD}(\mathrm{P})^{+}$reduction. Instead of using electrochemical means of production from $[\mathrm{Cp} * \mathrm{Rh}(\mathrm{bpy}) \mathrm{Cl}]^{+}$, it can be generated by ligand substitution using sodium formate as hydride source in a purely chemical regeneration system (Fig. 4) [21]. For NADH and NADPH regeneration at $38{ }^{\circ} \mathrm{C}$ the reported TOF is 82 . It should be noted that sodium formate had been introduced previously by Shaked and Whitesides [22] as a preparative stoichiometric reagent for the enzymatic regeneration of $\mathrm{NAD}^{+}$with formate dehydrogenase.

\section{Recent Developments for NAD(P)H and NAD(P) ${ }^{+}$ Regeneration}

The initial examples of $\mathrm{NAD}(\mathrm{P}) \mathrm{H}$ regeneration involving non-enzymatic steps, rely largely on rhodium - and ruthenium-based catalysts. Numerous other studies have been published in the past 20 years. Metals investigated for the 
Fig. 1 The first example of NADH regeneration involving a metal-catalysed step [1]

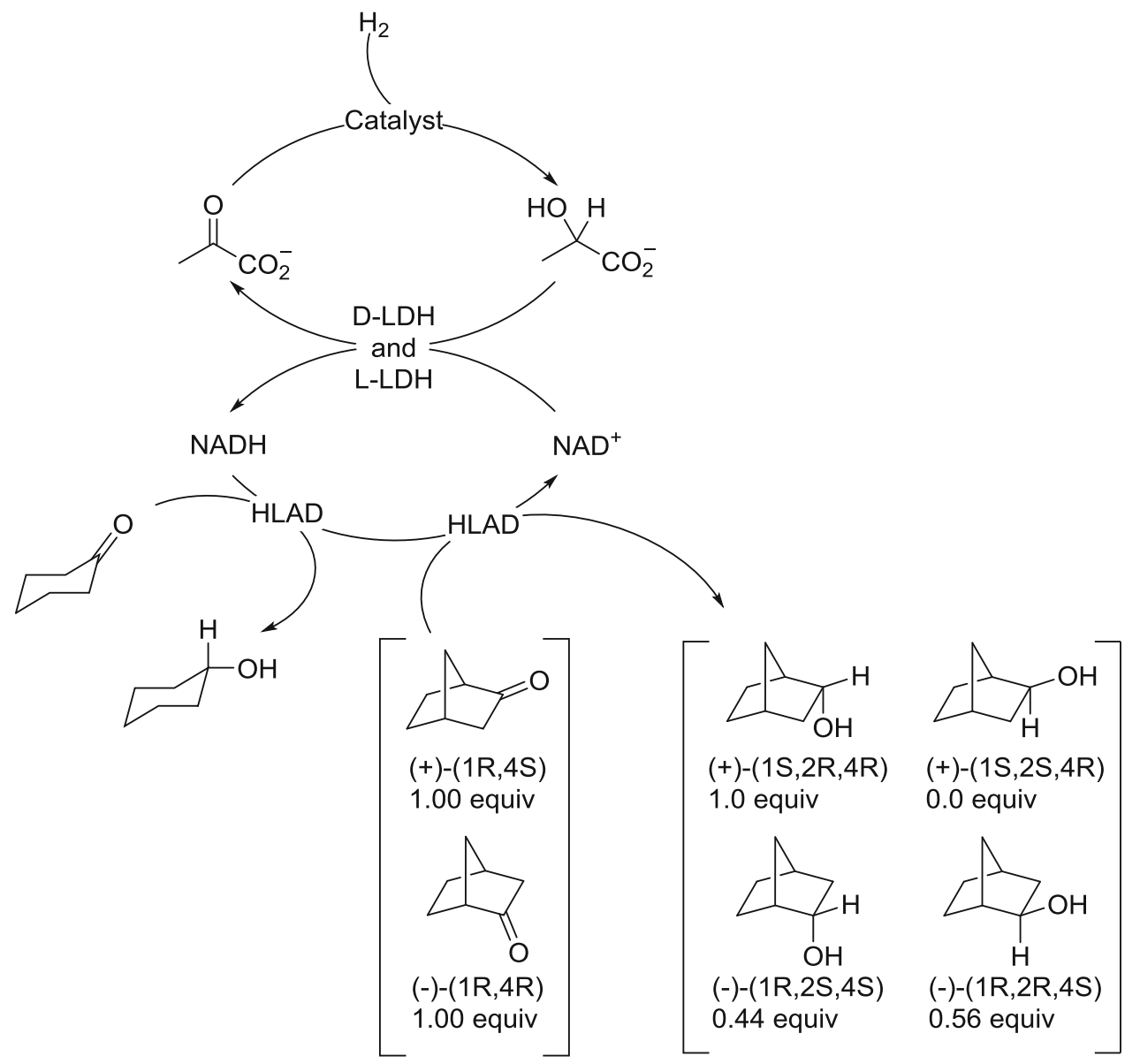

$\mathrm{D}(\mathrm{L})-\mathrm{LDH}=\mathrm{D}(\mathrm{L})$, lactate dehydrogenase; $\mathrm{HLADH}=$ horse liver alcohol dehydrogenase

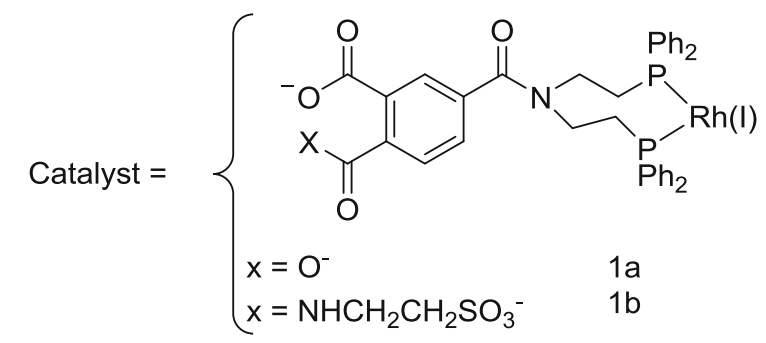

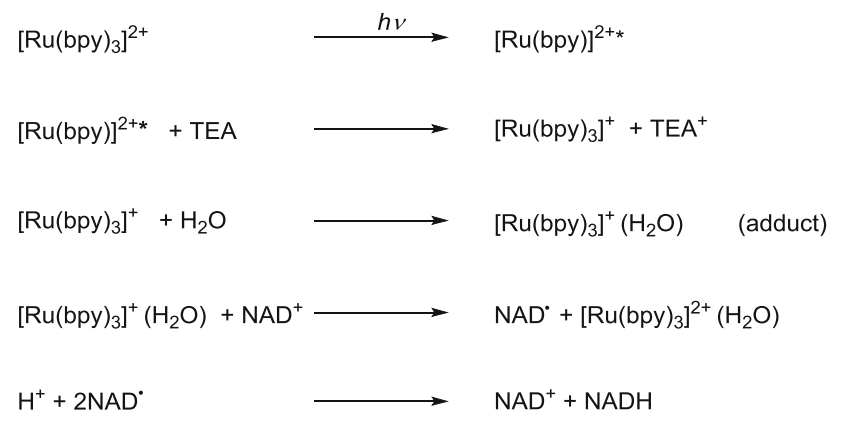

Fig. 2 Proposed photochemical NADH regeneration with $\left[\mathrm{Ru}(\mathrm{bpy})_{3}\right]^{2+}$ as catalyst [16]

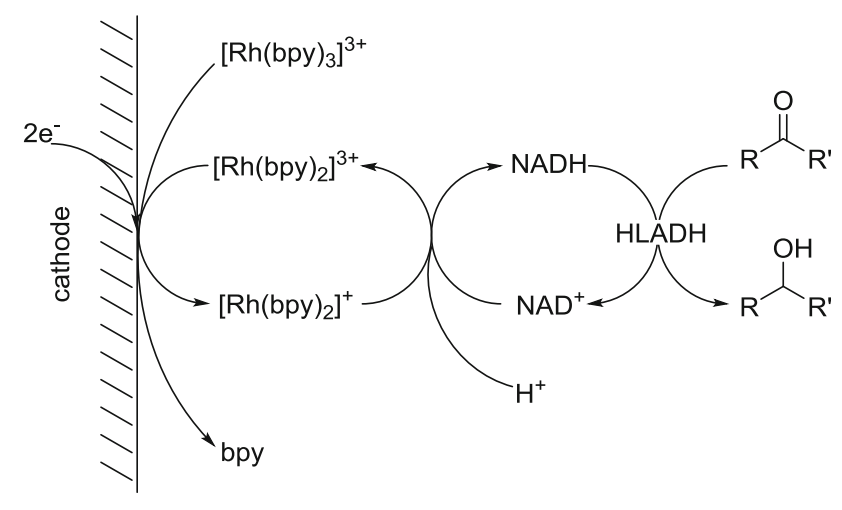

$\mathrm{HLADH}=$ horse liver alcohol dehydrogenase

Fig. 3 First example of an indirect electrochemical NADH regeneration using an organometallic mediator [19] 

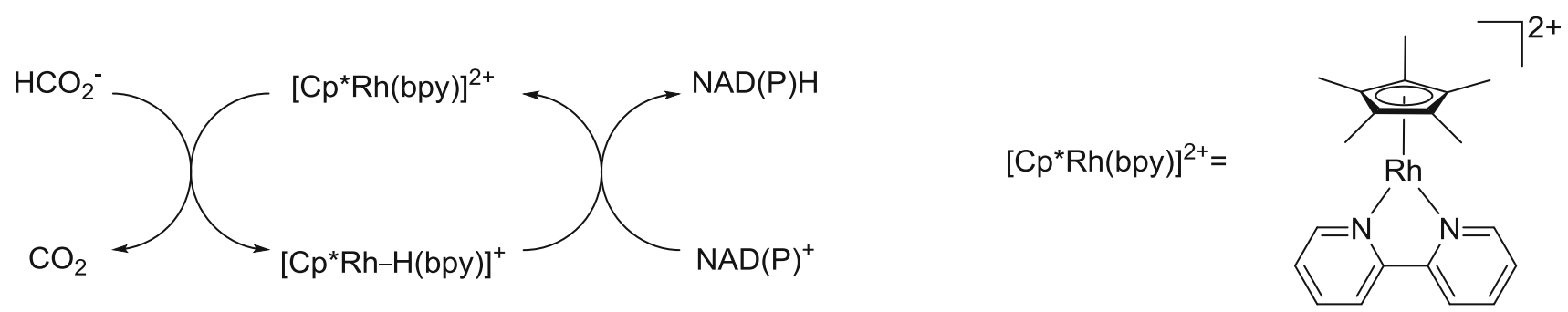

Fig. 4 Regeneration of $\mathrm{NAD}(\mathrm{P}) \mathrm{H}$ with $[\mathrm{Cp} * \mathrm{Rh}(\mathrm{bpy})]^{2+}$ using formate as chemical hydride source [21]

reduction and oxidation of $\mathrm{NAD}^{+} / \mathrm{NADH}$ or analogues (in solution or as electrode materials) include Co [23-25], Mn [26], $\mathrm{Fe}$ [27], $\mathrm{Pd}-\mathrm{Au}$ [28], Pt-C [29], Ni-C [29], $\mathrm{Cu}, \mathrm{Au}$, Pt-Au [30] Re [31, 32], Cu-Hg [33].

Recent reports feature increasingly iridium as the active metal center and address additionally the reverse reaction - the catalytic non-enzymatic oxidation of NAD(P)H under the simultaneous formation of metal hydrides.

Fukuzumi and co-workers [34] reported an efficient system where a $[\mathrm{C}-\mathrm{N}]$ cyclometalated complex $\left[\mathrm{Cp}^{*} \operatorname{Ir}(4-\right.$ (1H-pyrazol-1-yl)benzoic acid) $\left.\mathrm{H}_{2} \mathrm{O}\right] \mathrm{SO}_{4}$ can regenerate NADH under mild conditions ( $\mathrm{pH} 6-8$ ) utilizing $\mathrm{H}_{2}$ as the hydride source at room temperature and ambient pressure (Fig. 5). A TON of 9.3 at pD 8.0 was reported for an NMR experiment at high conversion after $90 \mathrm{~min}$. Under moderately acidic conditions, the same complex catalyzes the oxidation of NADH (i.e. the microscopic reverse reaction).

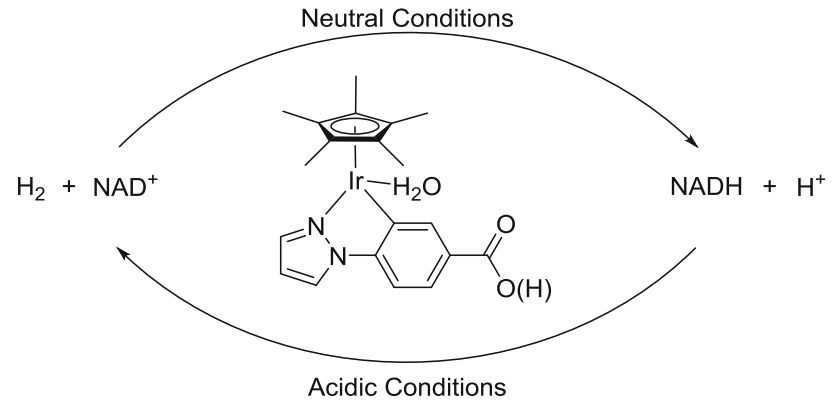

Fig. $5 \mathrm{NAD}^{+}$reduction (neutral conditions) and NADH oxidation (acidic conditions) with a cyclometallated pianostool complex [34]
The TON was determined with 6.3 after $20 \mathrm{~min}$ at a $\mathrm{pD}$ of 4.6 and at high conversion. This offers interesting opportunities for catalysis in a biological environment since the hydride is transferred to the metal complex, before combining with a proton from the solvent to release $\mathrm{H}_{2}$. It is believed that the change in $\mathrm{pH}$ leads to protonation of the carboxylate group on the ligand, which modifies the electronic properties of the ligand and alters the total charge of the complex. Regeneration of NADH with this complex can also be accomplished with alcohols as reductants under basic aqueous conditions ( $\mathrm{pH} 8.5-10)$ yielding the corresponding carbonyl compounds as 'byproducts' [35].

Shortly thereafter, Sadler showed that an organometallic ruthenium- or iridium catalyst can be employed for the reduction of pyruvate with NADH as the hydride source, thus mimicking the activity of lactate dehydrogenase [36]. In particular, the organometallic complexes $\left[\left(\eta^{6}-\mathrm{hmb}\right) \mathrm{Ru}(\mathrm{bmp})\right.$ $\mathrm{Cl}] \mathrm{PF}_{6}$ ( $\mathrm{hmb}=$ hexamethylbenzene, $\mathrm{bpm}=2,2^{\prime}$-bipyrimidine $)$ and $\left[\mathrm{Cp}^{\mathrm{xph}} \operatorname{Ir}(\mathrm{phen}) \mathrm{Cl}\right] \mathrm{PF}_{6} \quad\left(\mathrm{xph}=\eta^{5}-\mathrm{C}_{5} \mathrm{Me}_{4} \mathrm{C}_{6} \mathrm{H}_{5}\right.$, phen $=1,10$-phenanthroline) are two functional mimics of lactate dehydrogenase (for the iridium complex, a TON of 75 was reached) (Fig. 6). The complex [Cp*Ir(phen) $\mathrm{Cl}^{*} \mathrm{PF}_{6}$ was employed to catalyze the reduction of quinones in a biomimetic reaction of ubiquinone oxidoreductase [37]. Sadler analyzed the influence of the nature of the arene cap and the $\mathrm{N}, \mathrm{N}$-bidentate ligand for Noyori type ruthenium complexes. The activity of the complex for NADH oxidation was particularly high when benzene was used as an arene cap and the chelating aminosulfonamide ligand carried electron poor sulfonamides [38]. The oxidation of NADH to $\mathrm{NAD}^{+}$was

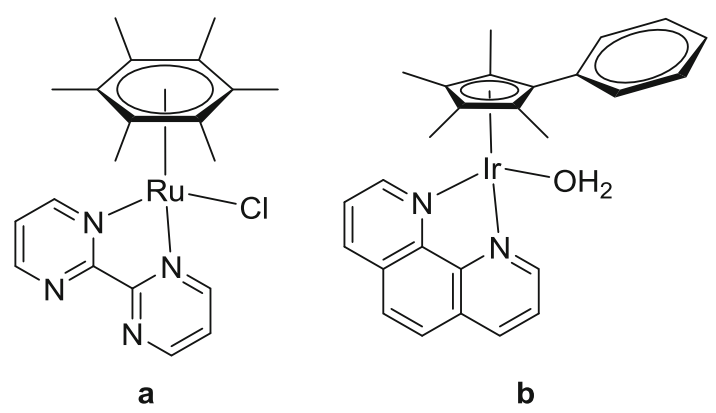

Fig. 6 NADH oxidation coupled with pyruvate reduction. The resulting systems present lactate dehydrogenase activity [36] 
(a)
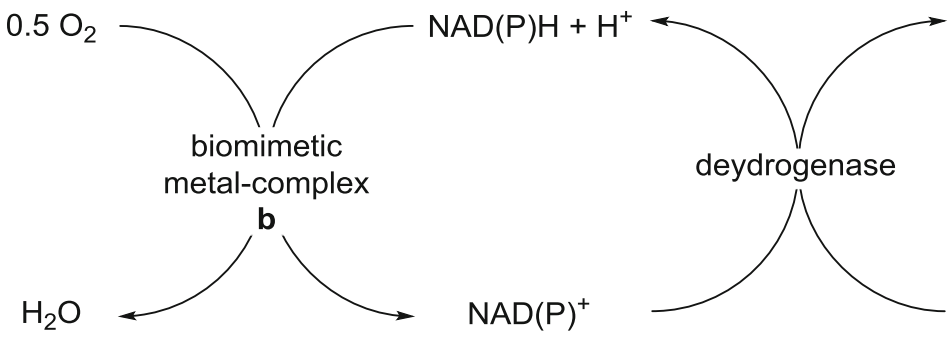

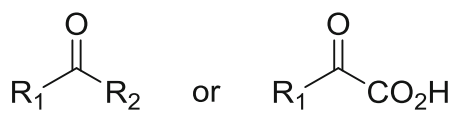

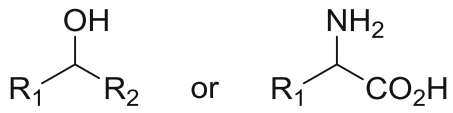

(b)

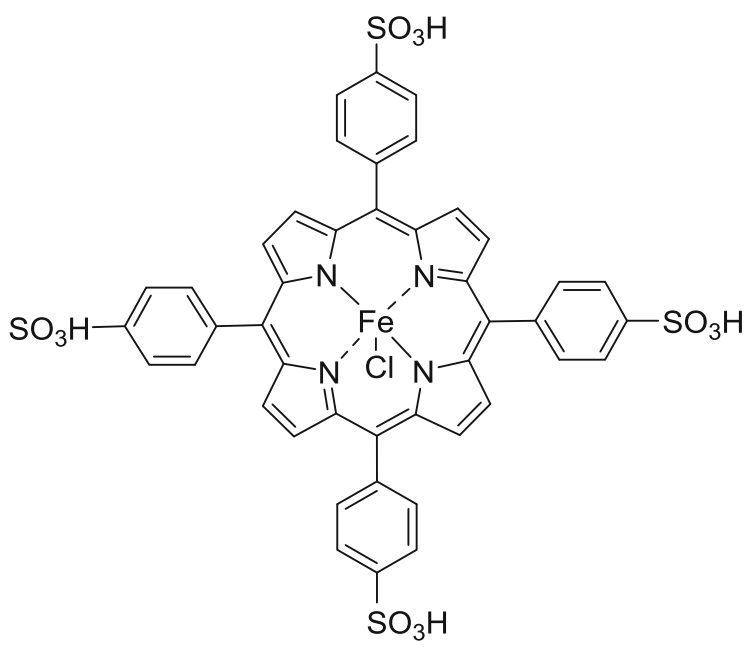

Fig. 7 a NAD(P)H oxidation by a biomimetic organometallic complex; b water soluble iron(III) porphyrin for NAD(P)H oxidation [41]
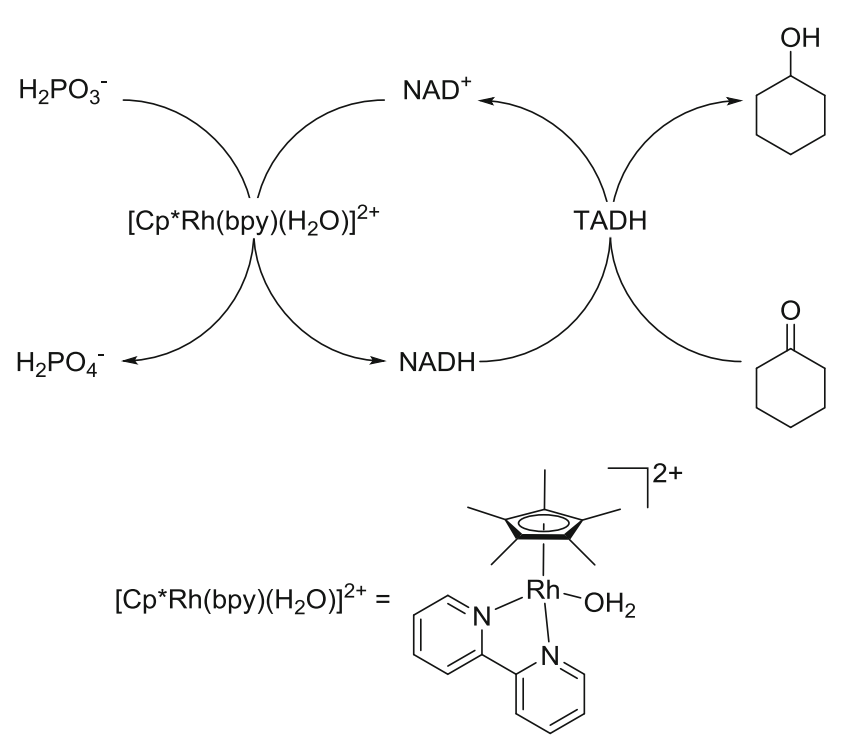

$\mathrm{TADH}=$ alcohol deydrogenase

Fig. 8 Chemical NADH regeneration using phosphite as hydride source, coupled with enzymatic alcohol dehydrogenase [42] further performed in aqueous solution with the osmium containing pianostool complex $\left[\left(\eta^{6}-p\right.\right.$-cym $\left.) \mathrm{Os}\left(\operatorname{Impy}-\mathrm{NMe}_{2}\right) \mathrm{Cl}\right] \mathrm{PF}_{6}$ (p-cym = para-cymene, Impy = iminopyridine $)$ [39]. In preceding work, Sadler and co-workers [40] reported the application of different ruthenium complexes for the generation of NADH under physiological conditions using formate as reducing agent.

An iron(III) porphyrin complex was introduced by Gröger for the oxidation of $\mathrm{NAD}(\mathrm{P}) \mathrm{H}$ [41]. This water soluble organometallic catalyst is able to oxidize both $\mathrm{NADH}$ and $\mathrm{NAD}(\mathrm{P}) \mathrm{H}$ with molecular $\mathrm{O}_{2}$ from air as the electron acceptor reaching a TON of 48-50 (Fig. 7). Efficient alcohol oxidation was achieved in conjunction with an alcohol dehydrogenase. Tests for $\mathrm{H}_{2} \mathrm{O}_{2}$ were negative, which accordingly did not need to be decomposed by the addition of a catalase. No mutual deactivation of metalloporphyrin and enzyme was reported.

Hollmann has been very active in the field of cofactor regeneration. He recently reported on coupling the wellestablished $\left[\mathrm{Cp} * \mathrm{Rh}(\mathrm{Bpy})\left(\mathrm{H}_{2} \mathrm{O}\right)\right]^{2+}$ catalyst for $\mathrm{NADH}$ regeneration with cyclohexanone reduction catalysed by alcohol dehydrogenase from thermophile Thermus sp. 
ATN1 (TADH) (Fig. 8). Instead of formate, he relied on phosphite as the stoichiometric reducing agent reaching a TOF of $21 \mathrm{~h}^{-1}$ [42]. Phosphite had previously been reported for enzymatic NADH regeneration with phosphite dehydrogenase [43]. While the authors observe product inhibition for the enzyme, no inactivation of the rhodium complex or of the enzyme was mentioned.

Hollmann and co-workers [44] also reported the use of a Noyori-type rhodium catalyst [Cp* $\mathrm{Rh}(\mathrm{TsDPEN}) \mathrm{Cl}]$, immobilized on polyethylene solid support, for the regeneration of NADH with a TOF of $2.5 \mathrm{~h}^{-1}$.

A photochemical approach employing flavin as photosensitizer for the regeneration of NADH was reported by Park. Electrons are provided by TEOA and $\left[\mathrm{Cp} * \mathrm{Rh}(\mathrm{bpy})\left(\mathrm{H}_{2} \mathrm{O}\right)\right]^{2+}$ serves once again as organometallic mediator. The NADH regeneration system was coupled to an enzymatic reaction for the formation of L-glutamate from $\alpha$-ketoglutarate with GDH (L-glutamate dehydrogenase) (Fig. 9) [45]. No inactivation of enzyme or mediator was reported.
In a successive investigations, they used different photosensitizers such as Eosin-Y or dot-coated silica beads, the former also in conjunction with $\mathrm{NAD}^{+}$analogues [46, 47]. A related photochemical regeneration of NADPH was recently coupled with cytochrome P450 catalyzed the O-dealkylation. In this case, the author mention the inactivation of the cytochrome $\mathrm{P}-450$ by $\left[\mathrm{Cp} * \mathrm{Rh}(\mathrm{bpy})\left(\mathrm{H}_{2} \mathrm{O}\right)\right]^{2+}[48]$.

\section{Mutual Inactivation of the Organometallic Catalyst and the Enzyme}

A challenge, often encountered in combining transition metal-based $\mathrm{NAD}(\mathrm{P}) \mathrm{H}$ regeneration with enzymatic $\mathrm{NAD}(\mathrm{P}) \mathrm{H}$-dependent processes is the mutual deactivation of the organometallic catalyst and the enzyme.

Some of the publications summarized above, mention low TONs and suggest that this may be due to the limited compatibility of organometallic and enzymatic catalysts.
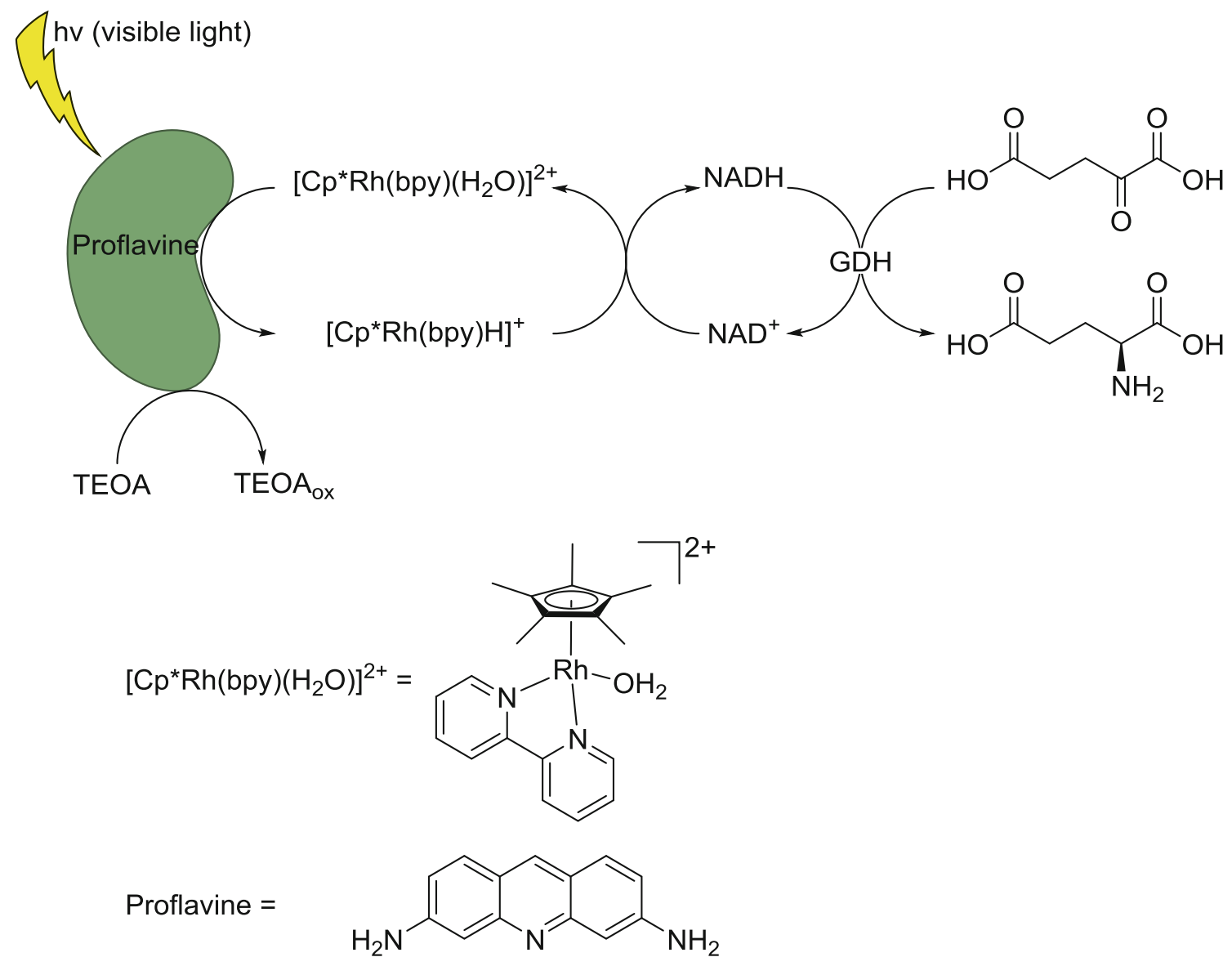

$\mathrm{GDH}=\mathrm{L}-$ Glutamate deydrogenase

Fig. 9 NADH regeneration induced by visible light, mediate from organometallic rhodium catalyst, coupled with an enzymatic L-glutamate dehydrogenase [45] 
We present below a selection of studies aimed at addressing this problem specifically.

To the best of our knowledge, Schmid and Fish were the first to highlight the mutual inactivation between $\left[\mathrm{Cp} * \mathrm{Rh}(\mathrm{bpy})\left(\mathrm{H}_{2} \mathrm{O}\right)\right]^{2+}$ and an $\mathrm{NADH}$ dependent enzyme [49]. The model system they investigated was the $\left[\mathrm{Cp} * \mathrm{Rh}(\mathrm{bpy})\left(\mathrm{H}_{2} \mathrm{O}\right)\right]^{2+}$ mediated regeneration of an NADH mimic with the enzymatic hydroxylation of 2-hydroxybiphenyl to the corresponding catechol catalysed by 2-hydroxybiphenyl-3-monooxygenase (HbpA) (Fig. 10).

Upon combining the organometallic cofactor regeneration system with the monooxygenase, no product formation was detected. The authors suggest that the interaction between the accessible nucleophilic amino acid residues (i.e. lysine $\left(-\mathrm{NH}_{2}\right)$ and cysteine $(-\mathrm{SH})$ ) of the enzyme $(\mathrm{HbpA})$ and the soft metal center of the organometallic catalyst causes deactivation of the rhodium catalyst.

To overcome the problem, they immobilized the enzyme on a polymer support flanked with epoxide moieties which react with exposed nucleophilic amino acid residues. The resulting coupled system enabled substantial hydroxylation when natural $\mathrm{NAD}^{+}$was employed.

Lütz and coworkers investigated in detail the problem of mutual inactivation between the organometallic mediator $\left[\mathrm{Cp} * \mathrm{Rh}(\text { bpy })\left(\mathrm{H}_{2} \mathrm{O}\right)\right]^{2+}$ and an alcohol dehydrogenase from Lactobacillus brevis ( $L b-\mathrm{ADH})$ and proposed a compartmentalization of the two entities [50].

For this purpose, they scrutinized the interaction of the piano stool complex with isolated amino acids to evaluate their influence. Interestingly, he identified tryptophan, in addition to the traditional suspects histidine and cysteine, that lead to strong deactivation of the pianostool moiety. Compartmentalization was achieved by immobilizing the organometallic mediator used for the electrochemical regeneration as part of a water-soluble polymer and the enzyme on Sephabeads ${ }^{\circledR}$. Additionally, a cellulose membrane, permeable only to NADH and substrate, was introduced to physically separate both catalysts (Fig. 11). Based on recovered mediator after the reaction they calculated a feasible turnover number of $>200$.

Building on previous observations, Hollmann and coworkers investigated the inactivation of various enzymes upon addition of $\left[\mathrm{Cp}^{*} \mathrm{Rh}(\mathrm{bpy})\left(\mathrm{H}_{2} \mathrm{O}\right)\right]^{2+}$. In addition to the spatial separation described above, they scrutinized the use of coordinating buffers as a potential remedy to mutual inactivation. They found that addition of $\left(\mathrm{NH}_{4}\right)_{2} \mathrm{SO}_{4}$ leads to an increased compatibility between the enzyme and the pianostool catalyst $\left[\mathrm{Cp} * \mathrm{Rh}(\mathrm{bpy})\left(\mathrm{H}_{2} \mathrm{O}\right)\right]^{2+}$. Unfortunately, the catalytic NADH regeneration using formate was eroded. In stark contrast, the electrochemical regeneration in the presence of $\left(\mathrm{NH}_{4}\right)_{2} \mathrm{SO}_{4}$ remained satisfying [51].

More recently, Bergman, Raymond and Toste presented an original supramolecular compartmentalization strategy to prevent mutual inactivation. For this purpose, they encapsulated the pianostool moiety $\left[\mathrm{CpRu}(\mathrm{NCMe})_{2} \mathrm{PMe}_{3}\right]^{+}$ ( $\mathrm{Cp}=$ cyclopentadiene $)$ within a supramolecular tetrahedral host cage. As a proof of principle, they developed a tandem catalytic process where the organometallic guest $\left[\mathrm{CpRu}(\mathrm{NCMe})_{2} \mathrm{PMe}_{3}\right]^{+}$catalyses the isomerization of allylic alcohol to the corresponding aldehyde which is subsequently reduced by an alcohol dehydrogenase to the saturated alcohol. A formate dehydrogenase provides the
Fig. 10 Organometallic regeneration of an mimic NADH coupled with enzymatic monooxygenase [49]

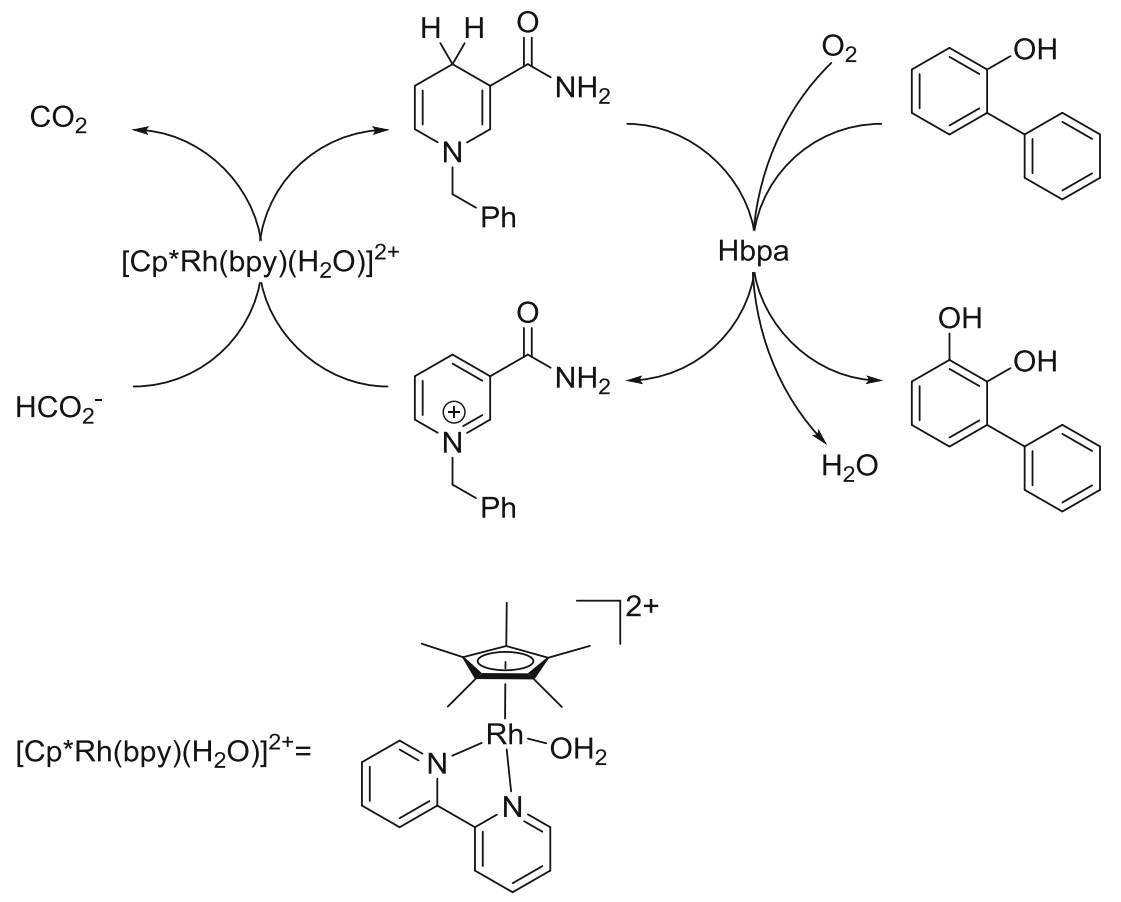


Fig. 11 Electroenzymatic reactor with separation of electrochemical NADHregeneration and enzymatic reaction for the production of $p$ chloro- $(R)$-phenylethanol with $\mathrm{Lb}-\mathrm{ADH}[50]$
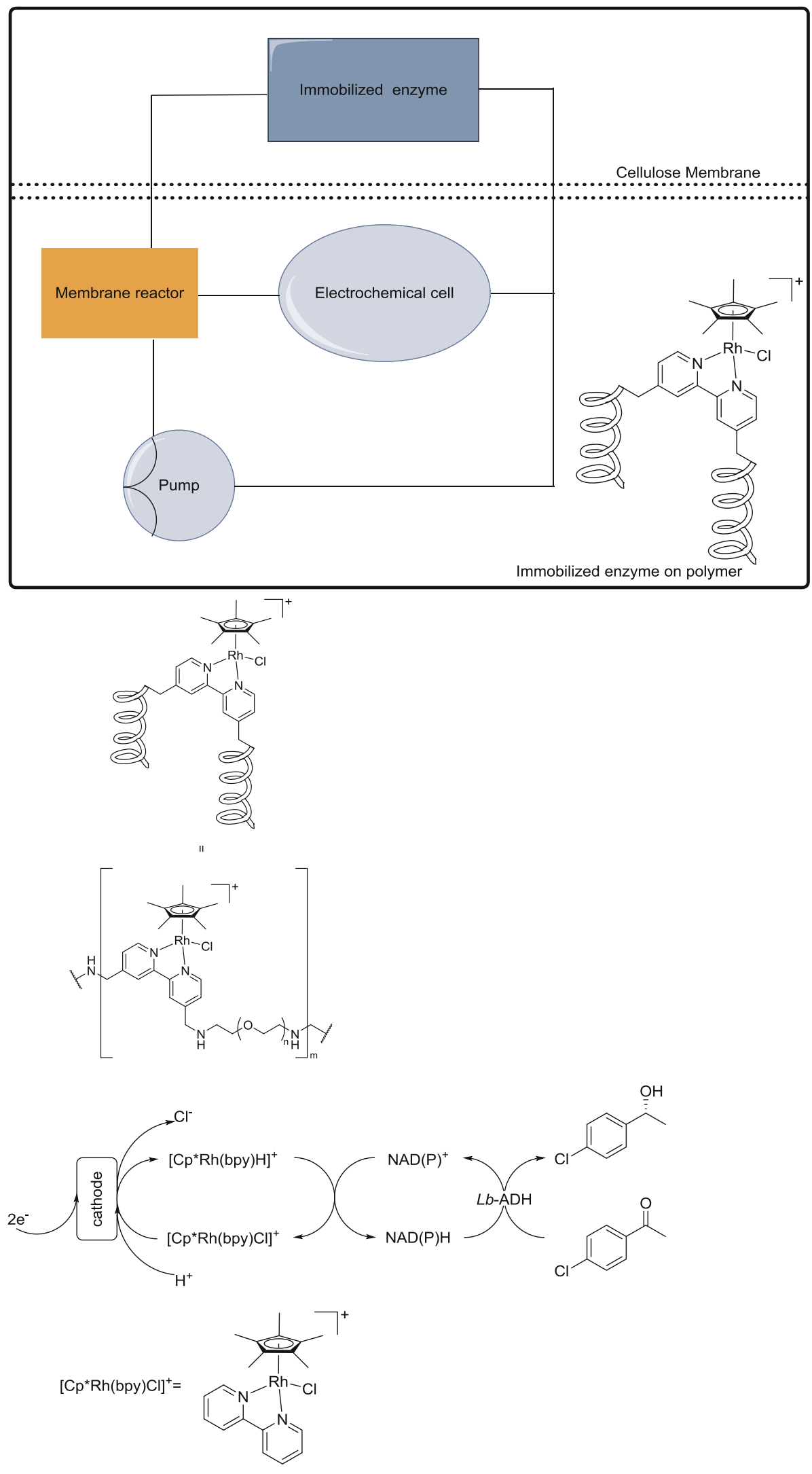

$\mathrm{Lb}-\mathrm{ADH}=$ Lactobacillus brevis alcohol dehydrogenase 
Fig. 12 Encapsulation of a ruthenium piano-stool catalyst in a supramolecular cage allows to combine a metal-catalyzed allylic isomerization with an enzyme cascade consisting of an NADPH-dependent alcohol dehydrogenase (ADH) and formate dehydrogenase (FDH) [52]
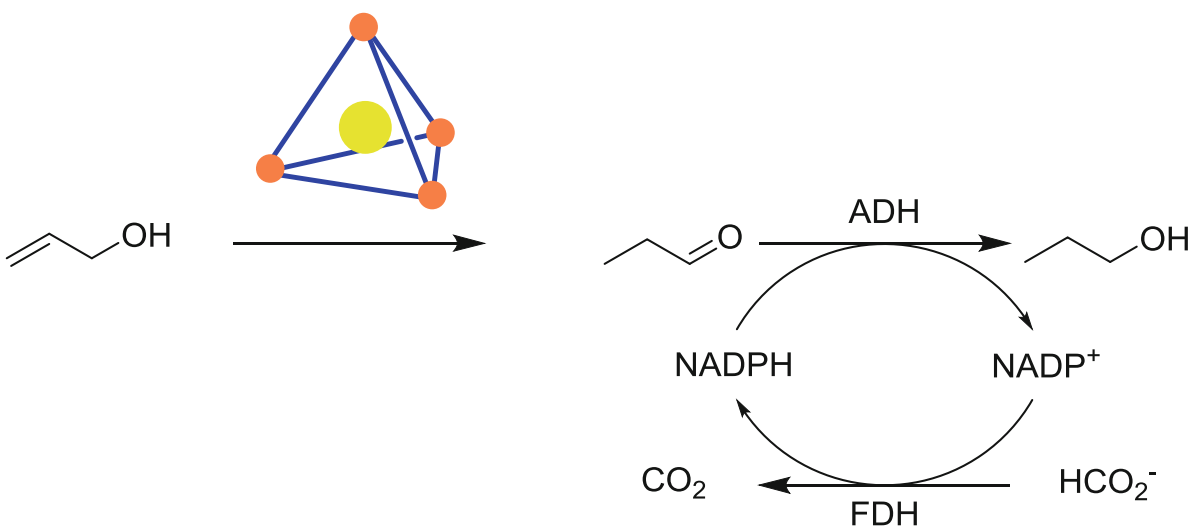<smiles>CN(C)[Pb](C)(C)C1CCC1</smiles>

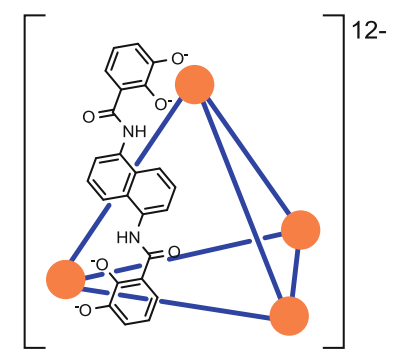

Host Guest $\mathrm{Ga}_{4} \mathrm{~L}_{6}$ each edge (blue) of tetrahedron rapresents a bisbidentate ligand and each vertex (orange) rapresent a Gallium(III) centre
Fig. 13 An artificial metalloenzyme for the NADH regeneration fully compatible with hydroxybiphenyl monooxygenase (HbpA) [53]

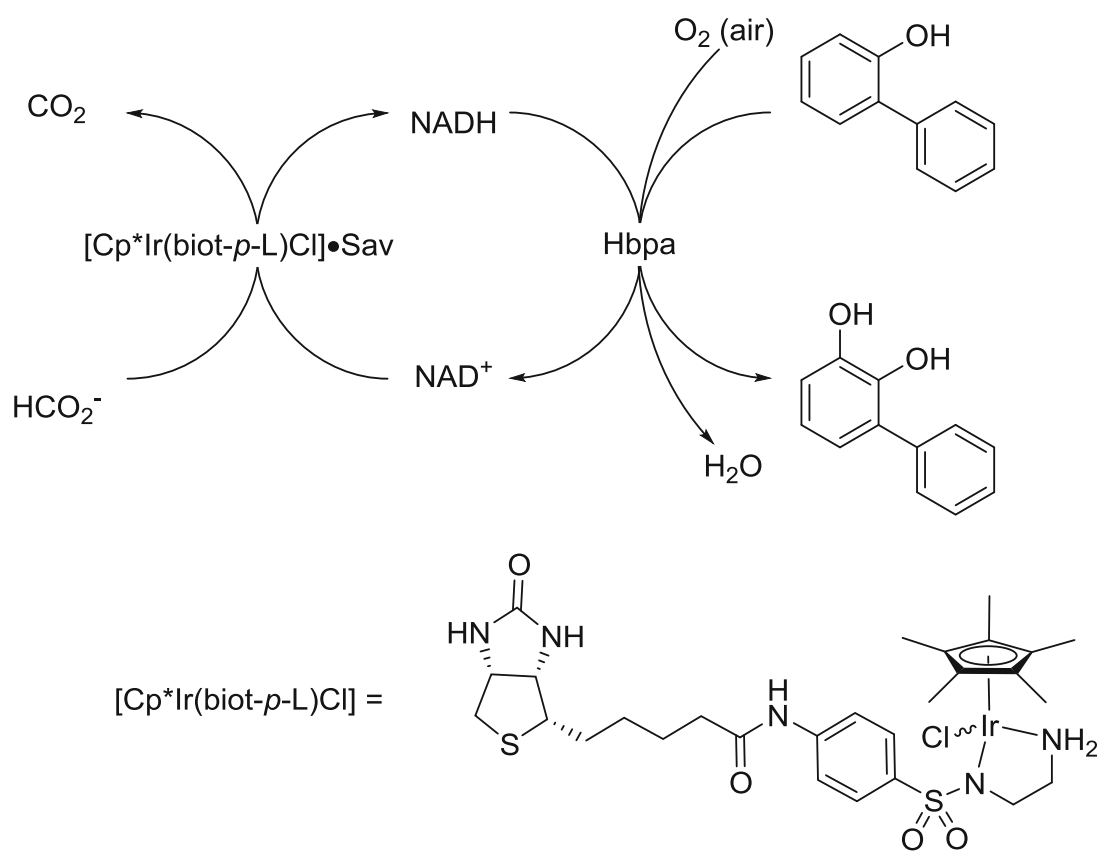

NADH equivalents for the process (Fig. 12) [52]. Although this system does not constitute an artificial NADH regeneration systems, it highlights the improved compatibility of an organometallic catalyst with enzymes upon incorporation into a supramolecular host, to avoid the interaction with free amino acid residues from enzyme. 
An alternative approach to address the problem of mutual inactivation was reported by Hollmann, Turner and Ward. They incorporated an Ir-piano stool complex for $\mathrm{NAD}^{+}$regeneration into streptavidin, thereby creating an artificial metalloenzyme and efficiently compartmentalizing the NADH dependent downstream enzyme and the Ir-complex [53]. The incorporation was realized by exploiting the biotin (strept)avidin technology [54].

In the same study it was observed that the catalyst $[\mathrm{Cp} * \operatorname{Ir}($ biot $-p-\mathrm{L}) \mathrm{Cl}]$ is significantly more active in NADH regeneration than the well-established $\left[\mathrm{Cp} * \mathrm{Rh}(\text { bpy })\left(\mathrm{H}_{2} \mathrm{O}\right)\right]^{2+}$. $\mathrm{By}$ incorporation of the iridum catalyst into a streptavidin mutant S112A, the system was coupled to the hydroxybiphenyl monooxygenase (HbpA) catalysed hydroxylation; efficient hydroxylation was achieved under relevant biological conditions ( $\mathrm{pH} 7.5,30^{\circ} \mathrm{C}$, open air) (Fig. 13) with a TON of $>100$ in respect to[Cp*Ir(biot- $p$-L)Cl].

\section{Outlook}

Having identified the underlying principles of mutual inhibition, several complementary compartmentalization strategies have been developed in recent years: polymer immobilization, selective membranes, supramolecular encapsulation and anchoring within a macromolecular scaffold. Thus far however, the most promising organometallic regeneration systems rely on precious metals: rhodium and iridium occupying a place of choice. The next step will be to implement the above strategies to base-metals.

Acknowledgments This research was made possible thanks to a grant from the European Union Seventh Framework Programme (FP7/2007-2013) under grant agreement $n^{\circ}$ FP7-PEOPLE-ITN-2008238531. Additional funding was provided by the Swiss National Science Foundation (200020_144354). TQ thanks Prof. Hollmann for enlightening discussions and hosting him in Delft to initiate this project. TRW thanks Umicore for a generous loan of $\left[\mathrm{Cp}^{*} \mathrm{IrCl}_{2}\right]_{2}$ and Prof. Cantor for the Sav gene.

\section{References}

1. Abril O, Whitesides GM (1982) Hybrid organometallic/enzymatic catalyst systems: regeneration of NADH using dihydrogen. J Am Chem Soc 104:1552-1554

2. Ruppert R, Herrmann S, Steckhan E (1987) Efficient indirect electrochemical in situ regeneration of NADH: electrochemically drive enzymatic reduction of pyruvate catalized by D-LDH. Tetrahedron Lett 28:6583-6586

3. Hollmann F, Arends IWCE, Buehler K (2010) Biocatalytic redox reactions for organic synthesis: nonconventional regeneration methods. ChemCatChem 2:762-782

4. Mcskimming A, Colbran SB (2013) The coordiantion chemistry of organo-hydride donors: new prospects for efficient multielectron reduction. Chem Soc Rev 42:5439-5488
5. Kochius S, Magnusson AO, Hollmann F et al (2012) Immobilized redox mediators for electrochemical $\mathrm{NAD}(\mathrm{P})^{+}$regeneration. Appl Microbiol Biotechnol 93:2251-2264

6. Hollmann F, Hofstetter K, Schmid A et al (2006) Non-enzymatic regeneration of nicotinamide and flavin cofactors for monooxygenase catalysis. Trends Biotechnol 24:163-171

7. Kohlmann C, Wolfgang M, Lütz S (2008) Electroenzymatic synthesis. J Mol Catal B Enzym 51:57-72

8. Rodriguez C, Lavandera I, Gotor V (2012) Recent advances in cofactor regeneration system applied to biocatalyzed oxidative process. Curr Org Chem 16:2525-2541

9. Truppo MD (2012) Cofactor recycling for enzyme catalyzed processes. Compre Chirality 7:46-70

10. Holtmann D, Schrader J (2007) Approaches to recycling and substituing $\mathrm{NAD}(\mathrm{P}) \mathrm{H}$ as a CYP cofactor. In: Schmid RD, Urlacher VB (eds) Modern biooxidation. Enzymes, reactions and applications. Willey, Weinheim, pp 265-290

11. Lütz S (2007) Transition metal-catalyzed regeneration of nicotinamide cofactors. In: de Vries JG, Elsevier CJ (eds) The handbook of homogeneous hydrogenation. Wiley, Weinheim, pp 1471-1482

12. Weckbecker A, Gröger H, Hummel W (2009) Regeneration of nicotinamide coenzymes: principles and applications for the synthesis of chiral compounds. In: Scheper T, Belkin S, Doran PM, Endo I, Gu MB, Hu WS, Mattiasson B, Nielsen J, Stephanopoulos GN, Ulber R, Zeng A-P, Zhong J-J, Zhou W (eds) Advances in biochemical engineering/biotechnology. Springer, Heidelberg, pp 195-242

13. Shaked Z, Barber JJ, Whitesides GM (1981) A Combined electrochemical/enzymatic method for in situ regeneration of NADH based on cathodic reduction of cyclic disulfides. J Org Chem 46:4100-4101

14. DiCosimo R, Wong C-H, Daniels Lacy et al (1981) Enzymecatalyzed organic synthesis: electrochemical regeneration of $\mathrm{NAD}(\mathrm{P}) \mathrm{H}$ from $\mathrm{NAD}(\mathrm{P})$ using methyl viologen and flavoenzymes. J Org Chem 46:4622-4623

15. Schmakel CO, Santhanam KSV, Elving PJ (1975) Nicotinamide adenine dinucleotide $\left(\mathrm{NAD}^{+}\right)$and related compounds. Electrochemical redox pattern and allied chemical behavior. J Am Chem Soc 97:5083-5092

16. Kiwi J (1981) Photochemical generation of reduced $\alpha$-nicotinamide-adenine dinucleotide (induced by visible light). J Photochem 16:193-202

17. Land EJ, Swallow AJ (1969) One-electron reactions in biochemical systems as studied by pulse radiolysis II riboflavin. Biochemistry 8:2117-2125

18. Wienkamp R, Steckhan E (1983) Selective generation of NADH by visible light. Angew Chem Int Ed 22:497

19. Wienkamp R, Steckhan E (1982) Indirect electrochemical regeneration of nadh by a bipyridinerhodium(I) complex as electron transfer agent. Angew Chem Int Ed 21:782-783

20. Franke M, Steckhan E (1988) Tris(2,2'-bipyridil-5-sulfonic acid)rhodium(III), an improved redox catalyst for the lightinduced and the electrochemically initiated enzymatic reduction of carbonyl compounds. Angew Chem Int Ed 27:265-267

21. Ruppert R, Herrmann S, Steckhan E (1988) Very efficient reduction of $\mathrm{NAD}(\mathrm{P})^{+}$with formate catalysed by cationic rhodium complexes. J Chem Soc Chem Commun 1:1150-1151

22. Shaked Z, Whiteside GM (1980) Enzyme-catalyzed organic synthesis: NADH regeneration by using formate dehydrogenase. J Am Chem Soc 102:7104

23. Fukuzumi S, Kitano T (1991) Mechanisms of reductive methylation of $\mathrm{NAD}^{+}$analogues by a trans-dimethylcobalt(III) complex. J Chem Soc Perkin Trans 2:41-45 
24. Hilt G, Steckhan E (1993) Transition metal complexes of 1,10phenanthroline-5,6-dione as efficient mediators for the regeneration of $\mathrm{NAD}^{+}$in enzymatic synthesis. J Chem Soc Chem Commun 94:1706-1707

25. Kim JA, Kim S, Lee J et al (2012) Photochemical production of NADH using cobaloxime catalysts and visible-light energy. Inorg Chem 51:8057-8063

26. Fukuzumi S, Kotani H, Prokop KA, Goldberg DP (2011) Electron- and hydride-transfer reactivity of an isolable manganese $(\mathrm{V})$ oxo complex. J Am Chem Soc 133:1859-1869

27. Fukuzumi S, Kotani H, Lee Y-M, Nam W (2008) Sequential electron-transfer and proton-transfer pathways in hydride-transfer reactions from dihydronicotinamide adenine dinucleotide analogues to non-heme oxoiron(IV) complexes and $p$-chloranil. Detection of radical cations of NADH analogues in acid-promo. J Am Chem Soc 130:15134-15142

28. Gopalan A, Ragupathy D, Kim H et al (2009) Pd (core)-Au (shell) nanoparticles catalyzed conversion of NADH to $\mathrm{NAD}^{+}$by UV-vis spectroscopy-a kinetic analysis. Spectrochimica Acta Part A 74:678-684

29. Ali I, Gill A, Omanovic S (2012) Direct electrochemical regeneration of the enzymatic cofactor 1,4-NADH employing nanopatterned glassy carbon/Pt and glassy carbon/Ni electrodes. Chem Eng J 188:173-180

30. Damian A, Maloo K, Omanovic S (2007) Direct electrochemical regeneration of NADH on $\mathrm{Au}, \mathrm{Cu}$ and $\mathrm{Pt}-\mathrm{Au}$ electrodes. Chem Biochem Eng Q 21:21-32

31. Kobayashi A, Takatori R, Kikuchi I et al (2001) Formation of novel 1:1 adducts accompanied by regioselective hydride transfer from transition-metal hydrido complexes to $\mathrm{NAD}(\mathrm{P})$ models. Organometallics 20:3361-3363

32. Kobayashi A, Konno H, Sakamoto K et al (2005) Transition metal complexes coordinated by an $\mathrm{NAD}(\mathrm{P}) \mathrm{H}$ model compound and their enhanced hydride-donating abilities in the presence of a base. Chem Eur J 11:4219-4226

33. Munteanu G, Dempsey E, Mccormac T, Munteanu C (2012) Fast cyclic voltammetry of redox system $\mathrm{NAD}^{+} / \mathrm{NADH}$ on the copper nanodoped mercury monolayer carbon fiber electrode. J Electroanal Chem 665:12-19

34. Maenaka Y, Suenobu T, Fukuzumi S (2012) Efficient catalytic interconversion between $\mathrm{NADH}$ and $\mathrm{NAD}^{+}$accompanied by generation and consumption of hydrogen with a water-soluble iridium complex at ambient pressure and temperature. J Am Chem Soc 134:367-374

35. Maenaka Y, Suenobu T, Fukuzumi S (2012) Hydrogen evolution from aliphatic alcohols and 1,4-selective hydrogenation of $\mathrm{NAD}^{+}$ Catalyzed by a $[\mathrm{C}, \mathrm{N}]$ and a $[\mathrm{C}, \mathrm{C}]$ cyclometalated organoiridium complex at room temperature in water. J Am Chem Soc 134: 9417-9427

36. Betanzos-lara S, Liu Z, Habtemariam A et al (2012) Organometallic ruthenium and iridium transfer-hydrogenation catalysts using coenzyme NADH as a cofactor. Angew Chem Int Ed 51: 3897-3900

37. Liu Z, Deeth RJ, Butler JS et al (2013) Reduction of quinones by NADH catalyzed by organoiridium complexes. Angew Chem Int Ed 52:4194-4197
38. Soldevila-barreda JJ, Bruijnincx PCA, Habtemariam A et al (2012) Improved catalytic activity of ruthenium-arene complexes in the reduction of $\mathrm{NAD}^{+}$. Organometallics 31:5958-5967

39. Fu Y, Romero JM, Habtemariam A et al (2012) The contrasting chemical reactivity of potent isoelectronic iminopyridine and azopiridine osmium(II) arene anticancer complexes. Chem Sci 3:2485-2494

40. Yan YK, Melchart M, Abtemariam A et al (2006) Catalysis of regioselective reduction of $\mathrm{NAD}^{+}$by ruthenium(II) arene complexes under biologically relevant conditions. J Biol Inorg Chem 11:483-488

41. Maid H, Böhm P, Huber SM et al (2011) Iron catalysis for in situ regeneration of oxidized cofactors by activation and reduction of molecular oxygen: a synthetic metalloporphyrin as a biomimetic $\mathrm{NAD}(\mathrm{P}) \mathrm{H}$ oxidase. Angew Chem Int Ed 50:2397-2400

42. Grau MM, Poizat M, Arends IWCE, Hollmann F (2010) Phosphite-driven, $\left[\mathrm{Cp} * \mathrm{Rh}(\mathrm{bpy})\left(\mathrm{H}_{2} \mathrm{O}\right)\right]^{2+}$-catalyzed reduction of nicotinamide and flavin cofactors: characterization and application to promote chemoenzymatic reduction reactions. Appl Organomet Chem 24:380-385

43. Vrtis JM, White AK, Metcalf WW et al (2001) Phosphite dehydrogenase: an unusual phosphoryl transfer reaction. J Am Chem Soc 123:2672-2673

44. De Torres M, Dimroth J, Arends IWCE et al (2012) Towards recyclable NAD(P)H regeneration catalysts. Molecules 17:9835-9841

45. Nam DH, Park CB (2012) Visible light-driven NADH regeneration sensitized by proflavine for biocatalysis. ChemBioChem 13:1278-1282

46. Lee SH, Ryu J, Nam DH, Park CB (2011) Photoenzymatic synthesis through sustainable $\mathrm{NADH}$ regeneration by $\mathrm{SiO}_{2}$-supported quantum dots. Chem Comm 47:4643-4645

47. Lee SH, Lee HJ, Won K, Park CB (2012) Artificial electron carriers for photoenzymatic synthesis under visible light. Chem Eur J 18:5490-5495

48. Lee SH, Kwon Y-C, Kim D-M, Park CB (2013) Cytochrome P450-catalyzed $O$-dealkylation coupled with photochemical NADPH regeneration. Biotechnol Bioeng 110:383-390

49. Lutz J, Hollmann F, Vinh $T$ et al (2004) Bioorganometallic chemistry: biocatalytic oxidation reactions with biomimetic $\mathrm{NAD}^{+} / \mathrm{NADH}$ co-factors and $[\mathrm{Cp} * \mathrm{Rh}(\mathrm{bpy}) \mathrm{H}]^{+}$for selective organic synthesis. J Organomet Chem 689:4783-4790

50. Hildebrand F, Lütz S (2009) Stable electroenzymatic processes by catalyst separation. Chem Eur J 15:4998-5001

51. Poizat M, Arends IWCE, Hollmann F (2010) On the nature of mutual inactivation between $\left[\mathrm{Cp} * \mathrm{Rh}(\text { bpy })\left(\mathrm{H}_{2} \mathrm{O}\right)\right]^{2+}$ and enzymes-analysis and potential remedies. J Mol Catal B Enzyme 63:149-156

52. Wang ZJ, Clary KN, Bergman RG et al (2013) A supramolucular approach to combining enzymatic and transition metal catalysis. Nat Chem 5:100-103

53. Köhler V, Wilson YM, Dürrenberger M et al (2013) Synthetic cascades are enabled by combining biocatalysts with artificial metalloenzymes. Nat Chem 5:93-99

54. Ward TR (2011) Artificial metalloenzymes based on the biotinavidin technology: enantioselective catalysis and beyond. Acc Chem Res 44:47-57 